\title{
Influência da adição da goma arábica em filmes isolados de polímero acrílico. Estudo das propriedades de intumescimento e de permeabilidade
}

\author{
Victor Gustavo Santos Gabas, Osvaldo Albuquerque Cavalcanti*
}

Laboratório de Tecnologia Farmacêutica, Departamento de Farmácia e Farmacologia, Universidade Estadual de Maringá

*Correspondência:

O. A. Cavalcanti

Laboratório de Tecnologia

Farmacêutica

departamento de Farmácia e

Farmacologia

Universidade Estadual de Maringá Av. Colombo, 5790 - Anexo Bloco P02

Maringá - PR

E-mail: oacavalcanti@uem.br
Goma arábica associada ao polímero acrílico Eudragit RS30D ${ }^{\circledR}$ na formação de filmes isolados foram obtidos e investigados como material potencialmente adequado à liberação modificada de fármacos. Foram preparadas dispersões aquosas de 4\% (p/v) e o citrato de trietila (20\% massa polímero acrílico) foi usado como plastificante. Dispersões foram vertidas em placa de Nylon revestida com Teflon ${ }^{\circledR}$ e colocadas em estufa a $60{ }^{\circ} \mathrm{C} . \mathrm{A}$ determinação do índice de intumescimento (Ii\%) em fluidos de simulação gástrica (FSG) e intestinal (FSI), além da permeabilidade ao vapor d'água (TVA) foram avaliadas. As dispersões propostas apresentaram habilidades filmogênicas. O polissacarídeo favoreceu, proporcionalmente à sua concentração, o grau de hidratação e a permeabilidade ao vapor d'água dos filmes formados. Estas particularidades observadas sugerem que os filmes constituídos por estas associações garantem acessibilidade com maior intensidade, quando comparado ao polimetacrilato individualmente, condição essa indispensável para uma biodegradação efetiva, em especial às regiões distais do trato gastrintestinal.
Unitermos

- Goma arábica

- Filmes isolados

- Polimetacrilato

\section{INTRODUÇÃO}

Os revestimentos farmacêuticos tornaram-se uma ferramenta importantíssima na elaboração de novos sistemas terapêuticos, prioritariamente voltados à promoção de uma liberação modificada de fármacos. Geralmente os polímeros utilizados na formação das películas visando à fabricação de formas farmacêuticas revestidas exigem a aplicação de solventes orgânicos acarretando elevação dos custos materiais e de instalações, podendo gerar comprometimentos ambientais aliado ao risco de explosões. $\mathrm{Na}$ última década, tem havido forte favorecimento dos investimentos em novas tecnologias voltadas a suprimir o uso de solventes orgânicos por preparações poliméricas em base aquosa. Os pseudolatex são dispersões coloidais de polímeros insolúveis em meio aquoso, tendo o diâmetro das partículas papel decisivo na fabricação dessas dispersões. O processo de obtenção destes pseudolatex inicia-se na solubilização deste polímero em solvente adequado, introduzida a fase orgânica em emulsão aquosa graças à presença de agentes emulsionantes e estabilizantes. Após completa homogeneização o solvente é removido, obten- 
do-se dispersão da etilcelulose ou do composto acrílico em água em concentrações de $25 \%$ e $30 \%$, respectivamente, de sólidos. A larga utilização destes pseudolatex de derivados celulósicos ou acrílicos no campo farmacêutico deve-se à consagração histórica da aprovação pelos órgãos fiscalizadores e regulamentadores, aliado à sua ampla aplicabilidade no desenvolvimento de novos sistemas terapêuticos de ação sustentada e/ou controlada (Bodmeier, Paeratakul, 1994). Desde os anos oitenta, estudos foram levados a cabo por várias companhias e grupos de pesquisa farmacêutica visando desenvolver novos sistemas capazes de disponibilizar o fármaco especificamente em determinadas áreas do trato gastrintestinal (Vandamme et al., 2002).

As dispersões aquosas obtidas a partir da dissolução do polímero etilcelulose comercialmente denominadas Aquacoat ${ }^{\circledR}$ produzido pela FMC (EUA) ou Surelease ${ }^{\circledR}$ pela Colorcon (EUA), são exemplos clássicos da categoria de pseudolatex. O Eudragit NE, RS e/ ou RL da linha Eudragit $^{\circledR}$ (Röhm Pharma - Alemanha), também constituem dois pseudolatex de larga aplicação farmacêutica, especialmente envolvidos nos sistemas de liberação controlada. Estes compostos constituem derivados do ácido metacrílico, caracterizado como produto de excelente habilidade filmogênica. Nesta categoria dos derivados do ácido metacrílico, o Eudragit RS30D ${ }^{\circledR}$ necessita da presença de plastificante para que suas moléculas tenham uma boa coalescência durante o processo de formação do filme e o citrato de trietila (TEC) tem sido o plastificante de escolha. A inclusão deste plastificante permite redução da fragilidade e aumento da elasticidade do filme, alterando as propriedades físicas e mecânicas do polímero (Lehmann, 1997).

O uso de materiais poliméricos naturais também tem sido foco de grande atividade de pesquisa voltadas ao desenvolvimento de novas formas farmacêuticas sólidas orais de liberação modificada. Os polímeros naturais (polissacarídeos e/ou oligossacarídeos), devido a suas propriedades de baixa toxicidade, biodegradabilidade, características filmogênicas, facilidade de derivatização, disponibilidade e baixo custo têm constituído um elemento de elevado interesse e destaque nas investigações voltadas à sua inclusão no grupo de excipientes farmacêuticos (Vandamme et al., 2002).

Nesta grande variedade de excipientes utilizados na pesquisa e desenvolvimento de novos sistemas para liberação modificada, existem inúmeras propostas de polímeros biodegradáveis, destacando-se nesse trabalho nosso interesse pelo polissacarídeo Goma arábica. A Goma arábica ou goma acácia é um produto obtido pela dessecação espontânea do exsudato dos troncos e dos ramos da Acácia Senegal (Linne). Sua inclusão no rol de excipientes farmacêuticos encontra reconhecimento e ampla aplicação na preparação de emulsões, suspensões, como ligante na fabricação de comprimidos convencionais, apresenta características de hidrossolubilidade, favorecendo o acesso microbiano, além de ser responsável pela camada aderente na fabricação de drágeas. Devido às potencialidades deste polissacarídeo quanto à degradação específica em regiões distais do TGI, existem fortes perspectivas da adição deste polímero a sistemas destinados ao revestimento colo-específicos. A Goma arábica juntamente como outros polissacarídeos obtidos de plantas tem sido fermentada por bactérias constituintes da microflora colônica, especialmente pelo gênero Bifidobacteria. Alguns polissacarídeos individualmente não possuem forte característica filmogênica, encontrando na associação com os polímeros sintéticos grandes recursos para sua aplicação (Hovgaard, Brondsted, 1996).

O colo, especialmente a primeira parte do intestino grosso, é afetado por numerosas afecções patológicas, como a constipação, doença de Crohn, colite ulcerativa, carcinomas e infecções. Os tratamentos recomendados incluem a administração de fármacos antiinflamatórios e quimioterápicos incluindo antibióticos. Alcançar uma ação farmacológica ideal destes fármacos significa transportá-las em concentrações adequadas sem que tenham qualquer liberação antes que alcancem a parte superior do colo. Na presente investigação propusemos associações poliméricas envolvendo o polissacarídeo Goma arábica (GA) e o derivado acrílico o Eudragit RS30D ${ }^{\circledR}$, avaliando o potencial de diferentes composições na formação de filmes. Foram realizados ensaios voltados à determinação das propriedades de intumescimento dos filmes obtidos em diferentes fluídos de simulação do TGI, além da avaliação da permeabilidade (TVA). A determinação das taxas da transmissão de vapor d'água (TVA) e grau de hidratação (Ii\%) constituem métodos de avaliação simples, porém imprescindíveis na caracterização de materiais poliméricos destinados ao revestimento farmacêutico. Este material foi investigado visando à identificação de composições potencialmente viáveis para confecção de filmes candidatos ao revestimento farmacêutico.

\section{MATERIAL E MÉTODOS}

\section{Material}

Eudragit RS 30D ${ }^{\circledR}$ (Röhm Pharma, Alemanha amostra gentilmente cedida pela Almapal S.A. São Paulo/SP); Goma arábica ${ }^{\circledR}$ (The Gum Arabic Company Ltda - Sudão), citrato de trietila (Morflex - EUA), amostra gentilmente cedida pela Almapal S.A. São Paulo/SP), Fluído 
de simulação gástrico (FSG) e intestinal (FSI) sem a presença de enzimas, preparados de acordo com a USP $23^{\circ}$ ed. 1995; agitadores magnéticos - Tecnal ${ }^{\circledR}$; bomba de vácuo; placa de Nylon ${ }^{\circledR}$ revestidas com Teflon ${ }^{\circledR}$; micrômetro (Mitutoyo $^{\circledR}$ - Japão); estufa; cronômetro; cúpulas de permeabilidade (Payne permeability cup, Braive Instruments, Liège, Bélgica). Os demais reagentes utilizados na preparação das soluções foram de grau analítico.

\section{Métodos}

\section{Associações poliméricas}

Conforme registrado na Tabela I, foram realizadas diferentes associações poliméricas visando obter os filmes isolados. Os componentes das formulações foram dispersos em água destilada de modo a obter concentração polimérica final de $4 \% \mathrm{p} / \mathrm{v}$.

TABELA I - Quantidade de polímeros (Eudragit RS30D + Goma arábica) usados para q.s.p. $100 \mathrm{~mL}$

\begin{tabular}{cc}
\hline $\begin{array}{c}\text { Eudragit RS30D } \\
\text { RS30D }\end{array}$ & $\begin{array}{c}\text { Goma arábica }(\mathbf{g}) \\
\text { GA }\end{array}$ \\
\hline $4,0(100 \%)$ & - \\
$3,6(90 \%)$ & $0,4(10 \%)$ \\
$3,2(80 \%)$ & $0,8(20 \%)$ \\
$2,8(70 \%)$ & $1,2(30 \%)$ \\
\hline
\end{tabular}

\section{Preparação dos filmes}

Os filmes foram preparados a partir de dispersões em base aquosa, usando um processo convencional para polímeros termoplásticos e termorrígidos, denominado "casting process" (Cavalcanti et al., 2002). Dispersões contendo Eudragit RS30D ${ }^{\circledR}$ (TEC 20\%) e Goma arábica foram colocadas sob agitação separadamente com tempos de 1 e 2 horas respectivamente, sendo em seguida misturadas formando uma dispersão a 4\% p/v, q.s.p $100 \mathrm{~mL}$ de água destilada e posteriormente agitada por $5 \mathrm{~h}$. Após completa homogeneização a dispersão foi transferida para um kitassato acoplado a bomba de vácuo para retirada das bolhas de ar. Três dispersões foram preparadas nas seguintes proporções: 90:10, 80:20 e 70:30 (Eudragit RS30D ${ }^{\circledR}$ : GA). Finalmente, alíquotas (volume $10 \mathrm{~mL}$ ) foram vertidas na placa de Nylon revestidas com Teflon ${ }^{\circledR}$ e colocadas na estufa usando temperatura mínima de formação de filmes igual a $60{ }^{\circ} \mathrm{C}$.

\section{Avaliação Macroscópica}

Os filmes formados foram cuidadosamente retirados e avaliados quanto às suas características morfológicas (ausência de bolha de ar, presença de rachaduras, homogeneidade). Após análises, as membranas selecionadas foram acondicionadas em dessecadores até o momento dos experimentos.

\section{Determinação da Espessura}

As espessuras dos filmes foram averiguadas com micrômetro Mitutoyo No 2046 F (Japão). Cada membrana foi verificada em quatro pontos diferentes escolhidos aleatoriamente para cada filme isolado.

\section{Determinação do Índice de Intumescimento (Ii\%)}

Os filmes das diferentes associações propostas foram cortados com aproximadamente $1 \mathrm{~cm}^{2} \mathrm{e}$, em seguida, distribuídos no interior de placas de Petri (devidamente identificadas). Posteriormente, as placas de Petri foram colocadas em estufa a $70{ }^{\circ} \mathrm{C}$ por período de aproximadamente de 15 horas visando à perda total de umidade. Após este tempo, as placas foram retiradas e mantidas em dessecadores durante a realização do experimento. As amostras das diferentes associações foram pesadas em balança analítica e imediatamente imersas em recipientes contendo FSG ou FSI e mantidas por diferentes intervalos de tempo à temperatura ambiente. Cumprido os intervalo de tempo pré-estabelecidos, as amostras foram removidas dos meios com o auxílio de pinça e cuidadosamente enxugadas entre duas folhas de papel de filtro e repesadas. O mesmo procedimento foi adotado para todas as outras amostras mantidas por períodos correspondentes aos intervalos de 1 a 10, 30 e 60 minutos de imersão. As características das cinéticas de intumescimento dos filmes representantes de todas as associações poliméricas investigadas foram quantificadas a partir do cálculo do índice de intumescimento (Ii\%), seguindo a equação sugerida por Cavalcanti et al. (2002).

$$
\mathrm{Ii} \%=\frac{\mathrm{Wi}-\mathrm{Ws}}{\mathrm{Ws}} \times 100
$$

em que Wi é o peso do filme após período de intumescimento e Ws representa o peso do filme seco.

\section{Estudo da Transmissão de Vapor d'água (TVA)}

O estudo da TVA foi desenvolvido de acordo com método $B$ da $A S T M$ designado E96-66. Inicialmente, no interior de cada cúpula de permeabilidade (Payne permeability cup, Braive Instruments, Liège, Bélgica) foram adicionados $10 \mathrm{~mL}$ de água destilada. Em seguida, os filmes a serem investigados, com diâmetro adequado, foram fixados às cúpulas individualmente. $\mathrm{O}$ conjunto (cúpula + água destilada + filme) foi pesado e armazenado no dessecador contendo sílica-gel. O dessecador foi 
deixado à temperatura e umidade ambiente. As cúpulas, em número de 3 para cada associação, foram pesadas nos intervalos de $0 ; 24 ; 48 ; 72 ; 96$ horas. A cada intervalo préestabelecido a sílica-gel foi permutada por outra desidratada. Os pesos perdidos pelas cúpulas nos respectivos intervalos de tempos foram registrados e aplicados para calcular a taxa de transmissão de vapor d'água transportada através das membranas. A TVA é padronizada para um período de 24 horas podendo ser calculada usando a seguinte equação (Van den Mooter et al. 1994):

$$
\mathrm{TVA}=\frac{\mathrm{g} 24}{\mathrm{ta}}
$$

em que g é o peso perdido, t representa o tempo em horas durante o qual o peso perdido foi acompanhado e a representa a área do filme, que foi de $0,001 \mathrm{~m}^{2}$.

Posteriormente, os valores percentuais das perdas dos pesos foram graficamente plotados versus os respectivos intervalos de tempo.

\section{RESULTADOS E DISCUSSÃO}

\section{Características morfológicas dos filmes}

As diferentes composições investigadas permitiram a formação de filmes com transparência e flexibilidade adequadas. Com o aumento da concentração do polissacarídeo Goma arábica as membranas passaram a apresentar variações em suas características macroscópicas, como transparência, e flexibilidade. Este polissacarídeo apresenta elevada solubilidade em meio aquoso e favorável capacidade filmogênica, gerando membranas de fácil manipulação $(4 \%$ p/v). Os resultados obtidos nesta etapa do trabalho permitem sugerir que a presença do plastificante (20\% TEC), além do favorecimento quanto à coalescência do EudragitRS30D ${ }^{\circledR}$, apresentou compatibilidade com a Goma arábica, nas associações aplicadas neste trabalho (90:10; 80:20 e 70:30). A análise das características macroscópicas permitiu evidenciar homogeneidade na distribuição dos polímeros envolvidos nas diferentes composições propostas, caracterizando perfeita e compatível dispersão dos constituintes, conforme registrado na Tabela II garantindo reprodutibilidade a partir da metodologia utilizada. Observaram-se valores homogêneos da espessura nos diferentes pontos da superfície das membranas, também foi observada influência nas espessuras proporcionais ao aumento da concentração da goma.

\section{Determinação das espessuras dos filmes}

Na Tabela III estão apresentados os diferentes valores registrados na determinação das espessuras dos filmes. Os valores obtidos confirmaram a reprodutibilidade do método adotado, garantindo a confecção de membranas com espessuras homogêneas e apropriadas aos ensaios.

TABELA II - Principais características macroscópicas observadas nas diferentes composições RS30D e Goma arábica $(\mathrm{n}=5)$

\begin{tabular}{cccccc}
\hline $\begin{array}{c}\text { Composição } \\
\text { (Eudragit RS30D } \\
\text { + Goma arábica) } \%\end{array}$ & $\begin{array}{c}\text { Separação } \\
\text { de fase }\end{array}$ & $\begin{array}{c}\text { Presença de } \\
\text { Rachadura }\end{array}$ & Bolha de ar & Transparência & Flexibilidade \\
\hline 100:0 & 0 & 0 & 0 & +++ & +++ \\
$90: 10$ & 0 & 0 & 0 & ++ & +++ \\
$80: 20$ & 0 & 0 & 0 & + & ++ \\
$70: 30$ & 0 & 0 & 0 & + & ++ \\
\hline
\end{tabular}

0 : Não observamos alterações; + : Levemente presente; ++ : Medianamente presente; $+++:$ Fortemente presente.

TABELA III - Valores das médias das espessuras dos filmes RS30D + G. Arábica (n=5)

\begin{tabular}{ccc}
\hline Associações & Espessura $(\mathbf{m m})$ & Desvio Padrão \\
\hline $100 \%$ & 0,078 & $\pm 0,0171$ \\
$90: 10$ & 0,1311 & $\pm 0,003$ \\
$80: 20$ & 0,1602 & $\pm 0,004$ \\
$70: 30$ & 0,145 & $\pm 0,0210$ \\
\hline
\end{tabular}




\section{Determinação do índice de intumescimento (li\%)}

Os resultados dos experimentos para determinação do intumescimento são mostrados nas Figuras 1 e 2 tanto para FSG, quanto para FSI, respectivamente. Também, foi registrado influência do meio sobre o grau de hidratação das membranas. Amostras de filmes isolados, quando imersas em FSI, apresentaram maior capacidade de intumescimento do que no FSG. Para as composições contendo Goma arábica, foram registrados aumentos dos

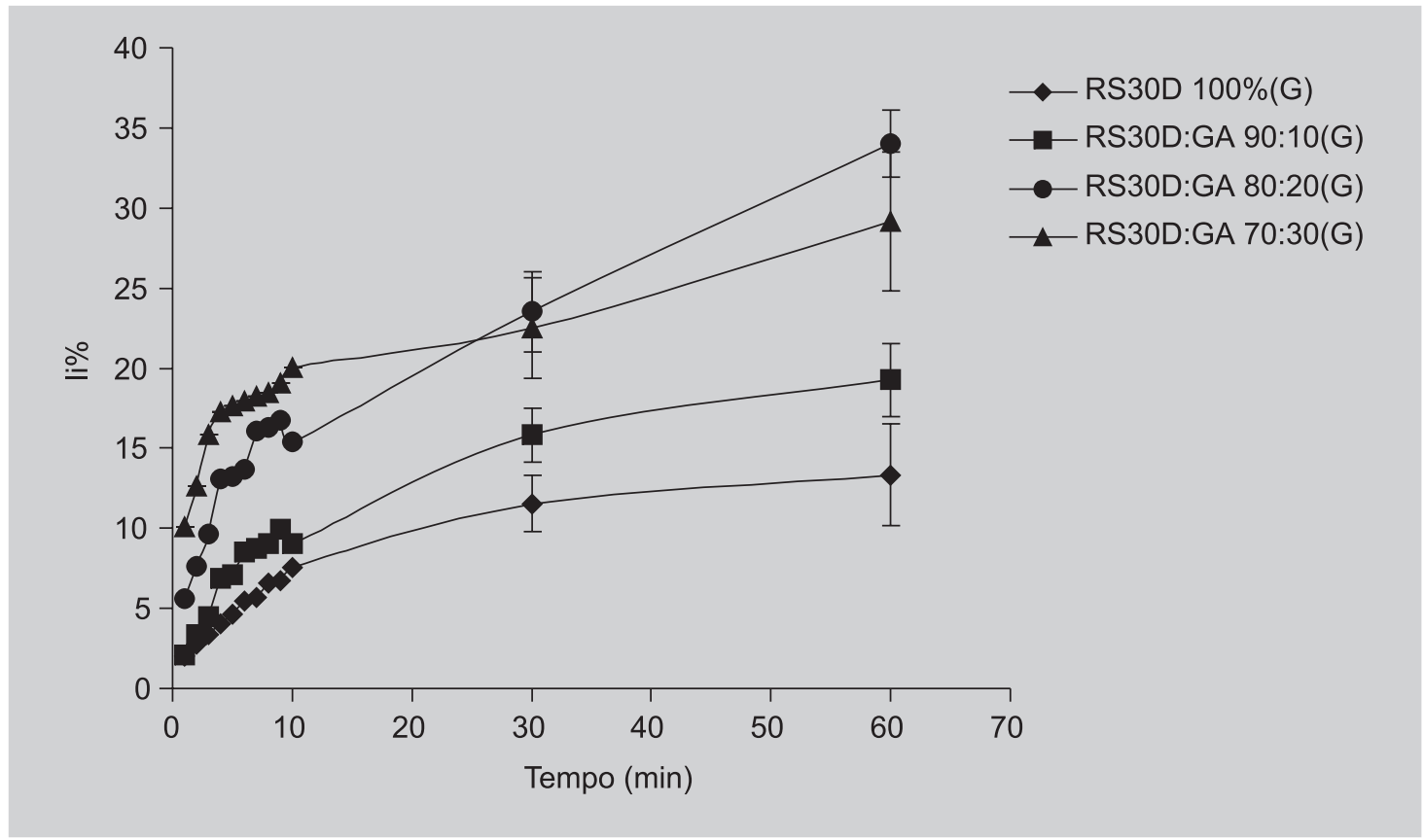

FIGURA 1 - Índice de intumescimento (I\%) em FSG(G) para diferentes associações de Eudragit RS30D:G.Arábica $(\mathrm{n}=3)$.

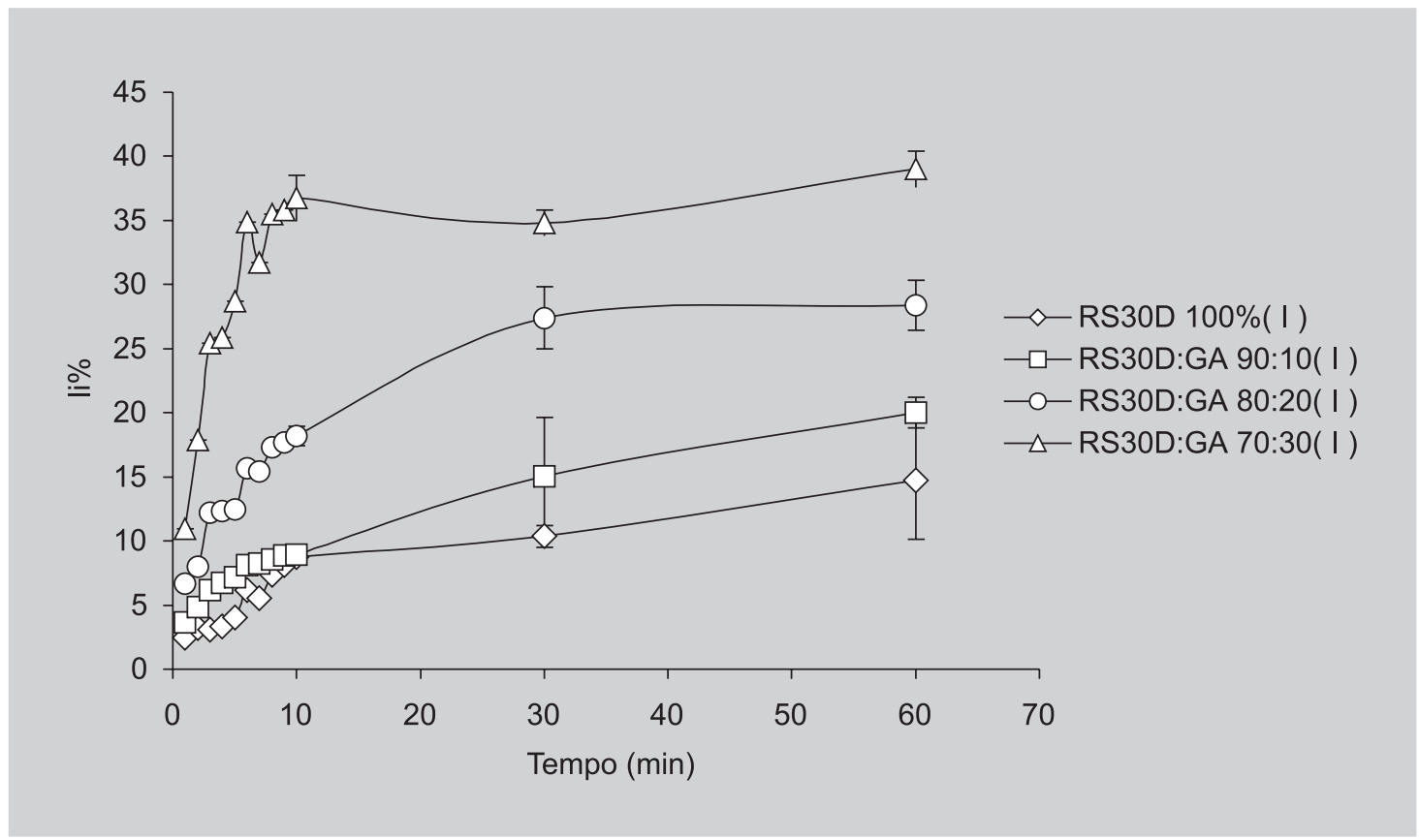

FIGURA 2 - Índice de intumescimento (Ii\%) em FSI( I ) para diferentes associações de Eudragit RS30D:G.Arábica $(\mathrm{n}=3)$. 
valores de hidratação proporcionais ao aumento da participação deste polissacarídeo. Filmes constituídos de concentração maior de GA (30\%) alcançaram proporcionalmente um grau maior de hidratação. Estas constatações foram registradas para ambos meios de simulação do TGI testados. No entanto, uma elevação adicional na hidratação foi observada quando os filmes foram imersos em meio de $\mathrm{pH}$ próximo ao neutro (SFI). Estudos anteriormente realizados com outro polissacarídeo galactomanana (polissacarídeo extraído de Prosopis juliflora, D.C.) também constataram resultados similares ao nosso. Os autores (Cavalcanti et al., 2002; Goycoolea et al. 1995) atribuem essa hidratação diferenciada às alterações estruturais do polissacarídeo, quando em meio alcalino, apresenta modificações em seu comportamento, como expansões estéricas e repulsões eletrostáticas entre os constituintes da sua cadeia.

\section{Transmissão de Vapor d' Água (TVA)}

A partir dos valores apresentados na Tabela IV, constatamos que às taxas de transmissão de vapor d'água, foram fortemente influenciadas pelos excipientes envolvidos nas composições dos filmes. O mesmo comportamento também está apresentado nas Figuras 3 E 4.

Os resultados registrados na Tabela IV demonstram que a TVA foi afetada pela composição do filme, variando de acordo com a concentração do polissacarídeo adicionado. $\mathrm{O}$ aumento na concentração da GA gerou aumento na taxa de transmissão de vapor d'água. Cavalcanti et

TABELA IV - Taxa de transmissão de vapor d'água e valores das perdas totais dos pesos das cúpulas com filmes Eudragit RS30D ${ }^{\circledR}+$ Goma arábica $(\mathrm{n}=3)$

\begin{tabular}{ccc}
\hline & Taxa de Transmissão de vapor d'água \\
Associação Polimérica & $\left(\mathbf{g} / \mathbf{m}^{\mathbf{2}} \mathbf{2 4} \mathbf{h}\right)$ & Peso perdido da cúpula $(\mathbf{g})$ ao final de $\mathbf{1 2 0} \mathbf{~ h}$ \\
\hline $100 \%$ & $238,849( \pm 27,552)$ & $1,359( \pm 0,1762)$ \\
$90: 10$ & $339( \pm 9,210)$ & $1,662( \pm 0,0595)$ \\
$80: 20$ & $522,073( \pm 24,631)$ & $2,724( \pm 0,561)$ \\
$70: 30$ & $588,861( \pm 26,265)$ & $3,033( \pm 0,154)$ \\
\hline
\end{tabular}

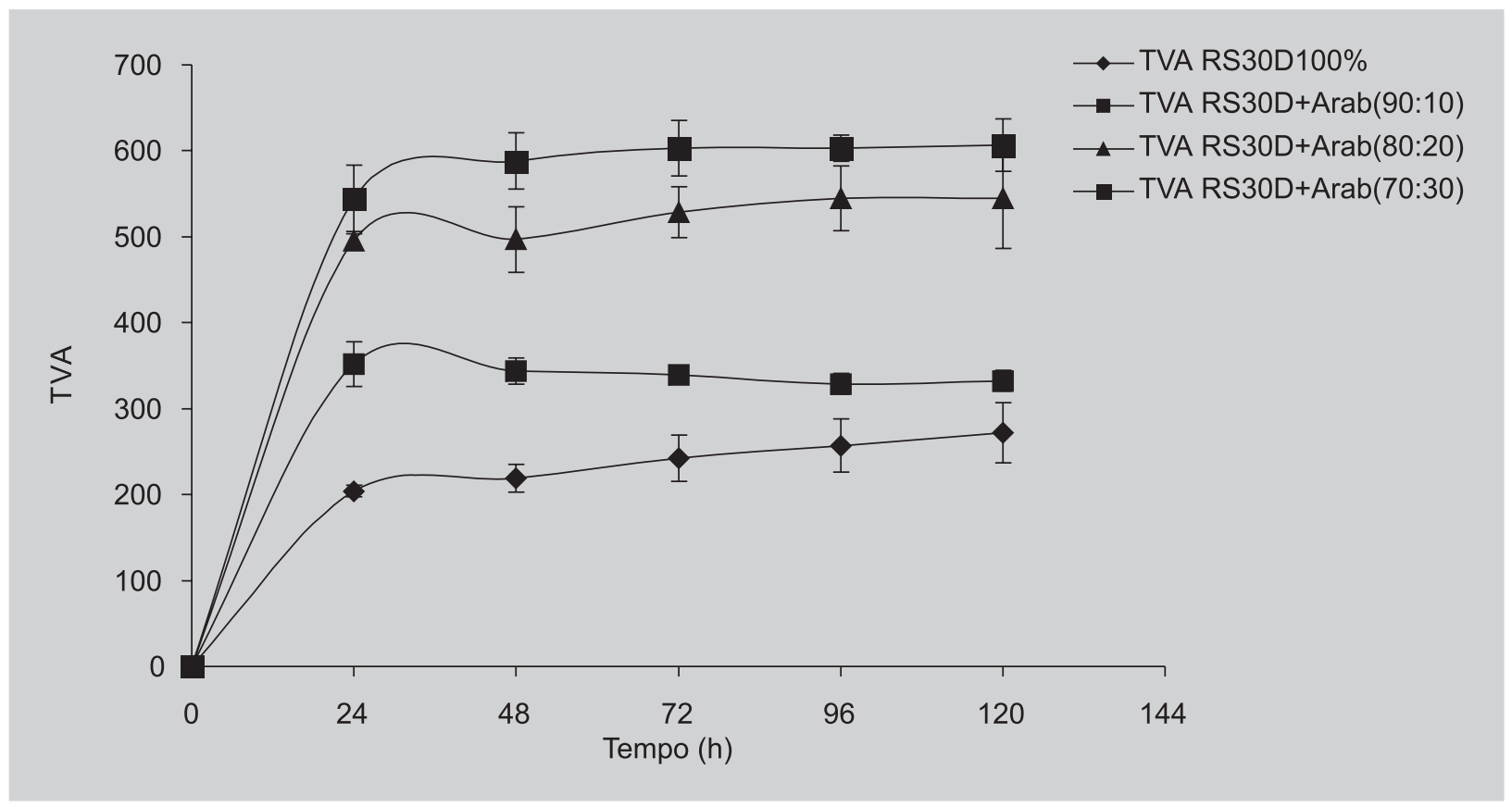

FIGURA 3 - Transmissão de Vapor d'água $\left(T V A=\mathrm{g} / \mathrm{m}^{2} /\right.$ dia $)$ do Controle 100\% RS30D e das associações 90:10, 80:20 e 70:30 RS30D + G. Arábica (n=3). 


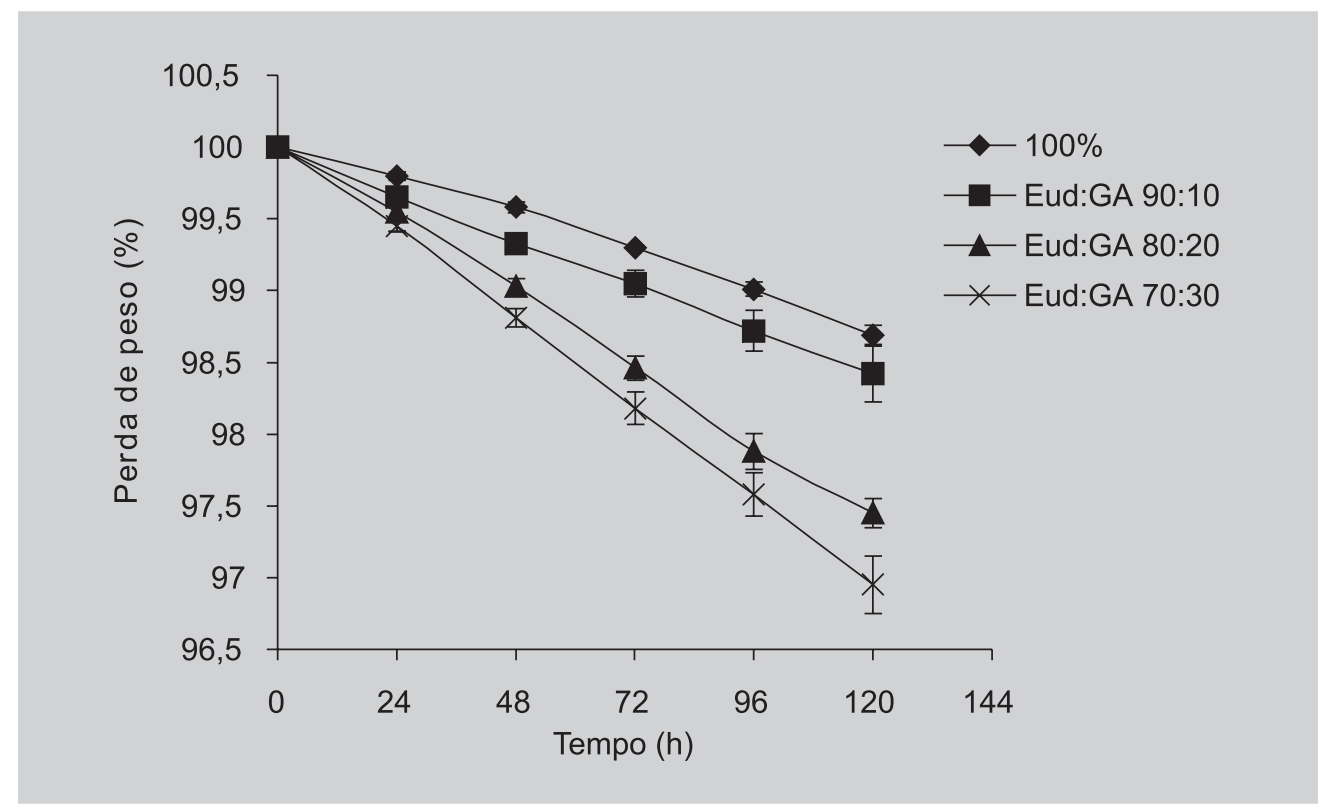

FIGURA 4 - Perda de peso das membranas através do TVA das diferentes composições RS30D + Goma arábica $(\mathrm{n}=3)$.

al. (2002), trabalhando com Eudragit $\mathrm{RS}_{0} 0 \mathrm{D}^{\circledR}$ associado à gatactomanana ou à inulina, observaram efeitos semelhantes no TVA proporcional ao aumento da concentração do polissacarídeo. Este fenômeno pode ser justificado pelo aumento da hidrofilicidade do sistema causado pela adição do polissacarídeo.

\section{CONCLUSÕES}

Os estudos mostraram que a incorporação do polissacarídeo GA ao polimetacrilato Eudragit RS30D ${ }^{\circledR}$ em dispersão aquosa gerou alterações nas propriedades dos filmes formados, quando comparados ao controle $(100 \%)$, sendo estas dependentes e proporcionais ao aumento da concentração da GA. O Eudragit RS30D ${ }^{\circledR}$, por estar em maior concentração, constitui a base da dispersão polimérica, permitindo proteção ao sistema tanto frente ao FSG como ao FSI. O aumento da quantidade do polissacarídeo GA favoreceu o grau de hidratação e a permeabilidade ao vapor d'água. Estas particularidades observadas quando da adição da GA permitem concluir que os filmes constituídos por estas associações poderão garantir acessibilidade ao filme, com maior intensidade quando comparado ao polimetacrilato individualmente, condição essa indispensável para biodegradação efetiva, em especial nas regiões distais do TGI.

\section{AGRADECIMENTOS}

Ao CNPq, pelo suporte financeiro através do pro- cesso 479122/2001-6. Ao Programa PIBIC/CNPq-UEM, pela bolsa de Iniciação Científica, processo 2181/02. À empresa Almapal (São Paulo/SP), pelas amostras dos produtos Eudragit RS30D ${ }^{\circledR}$ (Röhm Pharma, Alemanha) e citrato de trietila (Morflex - EUA). À empresa The Gum Arabic Company Ltda (Sudão), pela gentileza do envio de amostra da Goma arábica ${ }^{\circledR}$.

\section{ABSTRACT}

\section{Influence of arabic gum in acrylic polymer isolated} films. Study of swelling properties and permeability

Arabic gum combined with polymeric acrylic Eudragit $R S 30 D^{\circledR}$ in isolated films for film coating, were obtained and investigated as potential material adapted for drug delivery systems. They were prepared aqueous dispersions of $4 \%(p / v)$, the triethyl citrate $(20 \% \mathrm{w} / \mathrm{w}$ of the methacrylate polymer) it was used with plasticizer. Sample of dispersions were poured over plate of Nylon covered with Teflon and placed in an air circulated oven at $60^{\circ} \mathrm{C}$. Determination of the swelling index (Is\%) in fluids of gastric (SGF) or intestinal simulation or intestinal (SIF), and the permeability to the water vapour (TVA) were investigated. An increase in the amount of added polysaccharide favored the degree of hydration/swelling and permeability of the formed films. These observed particularities suggest that the films constituted by these combinations guarantee accessibility with larger intensity when compared individually to the polymethacrylate, 
condition that is indispensable for effective biodegradation, especially to the regions distal of gastrointestinal tract.

UNITERMS: Arabic gums. Isolated films. Polymethacrylate.

\section{REFERÊNCIAS BIBLIOGRÁFICAS}

BLANCHON, S.; COUARRAZE, G.; RIEG-FALSON, F.; COHEN, G., PUISIEUX, F. Permeability of progesterone and a synthetic progestin through methacrylic films. Int. J. Pharm., Amsterdam, v. 72, p. 1-10, 1991.

BODMEIER, R.; PAERATAKUL. O. Mechanical properties of dry and wet cellulosic and acrylic films prepared from aqueous colloidal polymer dispersions used in coating of solid dosage forms. Pharm. Res., New York, v. 11, n. 6, p.882-888, 1994.

CAVALCANTI, O. A.; PETENUCI, B.; BEDIN, A. C. Study of Swelling properties and Water Vapour Transmissions. Rev. Port.Farm., Lisboa, v. LI, n. 2, p. 93-96, 2001.

CAVALCANTI, O. A.; VAN DEN MOOTER, G.; CARAMICO SOARES, I.; KINGET, R. Polysaccharides as excipients for colon-specific coating. Permeability and swelling properties of casted films. Drug Dev. Ind. Pharm. New York, v. 28, n. 2, p. 157 - 164, 2002.

DAMIAN, F.; VAN DEN MOOTER, G.; SAMYN, C.; KINGET, R. In vitro biodegradation study of acetyl and metyl inulins by Bifidobacteria and inulinase. Eur. $J$. Pharm. Biopharm., Amsterdam, v. 47, p. 275-282, 1999.

DAVID, A.; YAGEN, B.; SINTOV, A.; RUBINSTEIN, A.; Acrylic polymers for colon-specific drug delivery, S.T.P. Pharma Sci., Paris, v. 7, p. 546-554, 1997.

GOYCOOLEA, F. M.; MORRIS, E.R.; GIDLEY, M.J.; Viscosity of galactomannans in alkaline and neutral $\mathrm{pH}$ : evidence and "hyperentanglement" in solution. Carbohyd. Polymer, Oxford, v. 27, p. 69-71, 1995.

GUPTA, V. K.; BECHERT, T. E.; DEUSCH, N. J.; HARIHARAN, M.; PRICE, J. C.; Investigation of Potential Ionic Interactions Between Anionic and Cationic Polymethacrylates of Multiple Coatings of Novel Colonic Delivery System. Drug Dev. Ind. Pharm., New York, v. 28, p. 207-215, 2002.
HOVGAARD, L.; BRONDSTED, H. Current applications of polysaccharides in colon targeting. Crit. Rev. Ther. Drug Carrier Syst., Boca Raton, v. 13, n. 3/4, p.185-223, 1996.

HYPPÖLÄ, R.; HUSSON, I.; SUNDHOLM, F. Evaluation of physical properties of plasticized ethyl cellulose films cast from ethanol solution. Part I. Int. J. Pharm., Amsterdam, v. 133, p.161-170, 1996.

LEHMANN, K. O. R. Chemistry and Application Properties of Polymethacrylate Coating Systems. In: MCGINITY, J. W., ed. Aqueous Polymeric Coatings for Pharmaceutical Dosage Forms, 2. ed., New York: Marcel Dekker, 1996. p.101-176.

OBARA, S.; McGINITY, J.W. Properties of free films prepared from aqueous polymers by a spraying technique. Pharm. Res., New York, v. 11, n. 11, p. 15621567, 1994.

RHODES, C. T.; PORTER, S. C. Coatings for ControlledRelease Drug Delivery Systems. Drug Dev. Ind. Pharm., New York, v. 24, n. 12, p. 1139-1154, 1998.

VANDAMME, T. F.; LENOURRY, A.; CHARRUEAU, C.; CHAUMEIL, J-C. The use of polysaccharides to target drugs to the colon. Carbohyd. Polymer, Oxford, v. 48, p. 219-231, 2002.

VAN DEN MOOTER, G.; SAMYN, C.; KINGET, R. Characterization of colon-specific azo polymers: A study of the swelling properties and the permeability of isolated polymer films. Int. J. Pharm., Amsterdam, v. 111, p.127136, 1994.

VERVOORT, L.; KINGET, R. In vitro degradation by colonic bacteria of inulinHP incorporated in Eudragit RS films. Int. J. Pharm., Amsterdam, v. 129, p.185-190, 1996.

Recebido para publicação em 23 de abril de 2003. 